Article

\title{
Integrated Management of Chive Gnats (Bradysia odoriphaga Yang \& Zhang) in Chives Using Entomopathogenic Nematodes and Low-Toxicity Insecticides
}

\author{
Xun Yan ${ }^{1,+}$, GuoYu Zhao ${ }^{1,2,+}$ and RiChou Han ${ }^{1, *}$ \\ 1 Guangdong Key Laboratory of Animal Conservation and Resource Utilization, Guangdong Public \\ Laboratory of Wild Animal Conservation and Utilization, Guangdong Institute of Applied Biological \\ Resources, No. 105 Xingang Road West, Guangzhou 510260, China; yanxun@giabr.gd.cn (X.Y.); \\ guoyu_zhao@163.com (G.Z.) \\ 2 Weifang Hongrun Agricultural Science \& Technology CO., LTD, Weifang Biomedical Industry Park, \\ Gaoxin 2nd Road, Weifang 261061, China \\ * Correspondence: hanrc@giabr.gd.cn; Tel.: +86-20-8419-1089 \\ + These authors contributed equally to this work.
}

Received: 30 April 2019; Accepted: 31 May 2019; Published: 5 June 2019

\begin{abstract}
Bradysia odoriphaga is a major pest that causes damage to chive production, and which has developed resistance to highly toxic chemical insecticides. Entomopathogenic nematodes (EPN) show a high potential for $B$. odoriphaga control. This study aimed to develop an effective management method against $B$. odoriphaga larvae, using EPN with low-toxicity insecticides. Fourteen selected insecticides had no significant effects on the survival and infectivity of Steinernema feltiae SN and Heterorhabditis indica LN2. Synergistic interactions were observed for imidacloprid and osthole with S. feltiae $\mathrm{SN}$ against B. odoriphaga larvae. Steinernema feltiae $\mathrm{SN}$ was more effective than $H$. indica LN2 against $B$. odoriphaga at 15 and $20^{\circ} \mathrm{C}$, and the addition of imidacloprid at $1 / 10$ recommended concentration (RC) significantly increased the efficacy of $S$. feltiae $\mathrm{SN}$. The year-round occurrence of the B. odoriphaga larvae in chive fields treated by EPN and imidacloprid at 1/10 RC was studied. Results showed that the application of EPN with imidacloprid at 1/10 RC successfully suppressed larval populations of $B$. odoriphaga in chive fields, thus significantly increasing the yield of chive. The practical method of applying EPN-imidacloprid combinations provided a cost-effective and environmental safety strategy for controlling $B$. odoriphaga larvae in chive production, which can reduce the usage of toxic chemical insecticides.
\end{abstract}

Keywords: Bradysia odoriphaga; Heterorhabditis indica; pest management; Steinernema feltiae; synergists

\section{Introduction}

The chive gnat, Bradysia odoriphaga Yang and Zhang (Diptera: Sciaridae), is a major insect pest in chive production in China [1]. Bradysia odoriphaga feeds on plants from seven families and on more than thirty species, and it also causes production losses in mushroom sheds [2]. Larvae of B. odoriphaga aggregate in the soil and feed on the roots and stems of the plant, causing plants to stunt or even die [3]. Bradysia odoriphaga has 4-6 overlapping generations per year, and the peak damage occurs in spring and autumn [2,4], which leads to chive production losses of $30 \%$ to $80 \%$ in North China [5].

Larvae of B. odoriphaga are cryptic in the soil, and therefore much more toxic insecticides are used by the farmer to maintain yields, which has led to heavy insecticide residues in the chives and the soil [6]. Over-use of toxic insecticides has also led to the development of insecticide resistance in 
B. odoriphaga, and it has developed widespread resistance to organophosphorus insecticides such as chlorpyrifos and phoxim $[7,8]$. New effective and environmentally friendly methods for controlling B. odoriphaga are urgently needed.

Entomopathogenic nematodes (EPN) of the genera Steinernema and Heterorhabditis (Rhabditida: Steinernematidae and Heterorhabditidae) have been successfully used to control some soil-dwelling and boring insect pests, because they can actively search for their hosts [9-12]. Earlier studies have showed that EPN had the potential to control B. odoriphaga. Two EPN species, S. feltiae and S. hebeiense, were found to have the ability to suppress the larval population of $B$. odoriphaga in chive fields to a level that is similar to phoxim treatment [3]. Heterorhabditis indica could also control the B. odoriphaga larvae in chive field, and the control effect could last for at least three months after a one-time application, which was more effective than phoxim application [13]. Although EPN have the potential to control B. odoriphaga, their efficacy in the field might not be stable, due to the influences from different environmental factors [12,14]. Further, when compared to common chemical insecticides, the cost of EPN remains too high for most of the chive growers in China [15]. Combining EPN with insecticides has contributed to the control of a number of economically important crop pests [15-19]. Therefore, the improvement of EPN efficacy by combining EPN with low-toxicity insecticides is an ideal strategy for the effective control of $B$. odoriphaga larvae.

Previous studies have indicated that EPN are compatible with different kinds of chemical insecticides, and some insecticides have been reported to be synergistic with EPN against white grub (Holotrichia oblita, Popillia japonica, Exomala (Anomala) orientalis, Cyclocephala spp., etc), whitefly, (Bemisia tabaci) and leafminer (Liriomyza huidobrensis, Tuta absoluta) [15-27]. The effect of S. feltiae SN with thiamethoxam to control B. odoriphaga was studied in chive fields in Tai'an, China [28]. However, better and cheaper synergistic insecticides should be screened before a practical method that involves the combination of EPN in insecticides to control B. odoriphaga in chive field is established. Furthermore, the dynamics of B. odoriphaga larvae in chive fields after EPN-insecticide applications should also be investigated for a longer period that covers the entire season of chive production, and the chive yield and production cost also needs to be compared with the control and insecticide treatments. The purpose of this study is to screen compatible insecticides that showed synergistic effects with EPN against larvae of $B$. odoriphaga, and to develop an environmentally friendly and cost-effective method of controlling B. odoriphaga in chive production.

\section{Materials and Methods}

\subsection{Nematodes}

Infective juveniles (IJs) of S. feltiae SN and H. indica LN2 were provided by Weifang Hongrun Agriculture Science and Technology Co., LTD, China. Survival of IJ were examined under a stereoscopic microscope before use, and they were considered dead when they showed no response after probing with a needle [26]. The background mortality of the IJ was below $10 \%$ throughout the study. All laboratory bioassays were repeated twice, using different batches of nematodes.

\subsection{Insects}

Larvae of B. odoriphaga were collected from a chive field located at Baijia Village, Gaozhai County, Zhangqiu District in Jinan city. The chive gnats were reared in $9 \mathrm{~cm}$ diameter Petri dishes, furnished with two layers of $9 \mathrm{~cm}$ diameter filter paper and a $2 \mathrm{~cm}$ length of chive stem, in the laboratory for 3-4 days. The fourth instar larvae of $B$. odoriphaga were used for bioassays [3,29].

The ninth to 11th instar larvae of yellow mealworm, Tenebrio molitor L., were purchased from the Binzhou Xinchong yellow mealworm breeding factory, China. The yellow mealworms were reared at $25 \pm 1{ }^{\circ} \mathrm{C}$ for 2 days after purchase, and used for the bioassay [30]. 


\subsection{Laboratory Bioassay}

\subsubsection{Insecticides}

Three kinds of insecticide used for the bioassay are listed in Table 1, which included chemical insecticides, botanical insecticides, and insect growth regulators. All of the insecticides were commercial formulations purchased from the Chinese market, and they are commonly used in Chinese vegetable production.

Table 1. Low-toxicity insecticides used in the study.

\begin{tabular}{|c|c|c|c|}
\hline Insecticide $^{1}$ & Main Component & Manufacturer & $\begin{array}{l}\text { Recommended } \\
\text { Field Rate }\end{array}$ \\
\hline \multicolumn{4}{|l|}{ Chemical insecticide } \\
\hline Chlorantraniliprole SC $20 \%$ & chlorantraniliprole & DuPont USA & $150 \mathrm{~mL} \cdot \mathrm{ha}^{-1}$ \\
\hline Chlorfenapyr SC $10 \%$ & chlorfenapyr & BASF & $750 \mathrm{~mL} \cdot \mathrm{ha}^{-1}$ \\
\hline Imidacloprid WG 70\% & imidacloprid & Bayer & $45 \mathrm{~g} \cdot \mathrm{ha}^{-1}$ \\
\hline Myclobutanil EC $12.5 \%$ & myclobutanil & Kaifeng Tianwei Biochemical Co., Ltd. & $450 \mathrm{~mL} \cdot \mathrm{ha}^{-1}$ \\
\hline Triadimefon GR 15\% & triadimefon & $\begin{array}{l}\text { Sichuan Guoguang Agriculture and Chemistry } \\
\text { Co., Ltd. }\end{array}$ & $900 \mathrm{~g} \cdot \mathrm{ha}^{-1}$ \\
\hline \multicolumn{4}{|l|}{ Botanical insecticide } \\
\hline Azadirachtin SC $0.3 \%$ & azadirachtin & Chengdu Green the High-Tech Co., Ltd. & $2250 \mathrm{~mL} \cdot \mathrm{ha}^{-1}$ \\
\hline Matrine SC $0.5 \%$ & matrine & $\begin{array}{l}\text { Beijing Green Agricultural Science and } \\
\text { Technology Group Co., Ltd. }\end{array}$ & $1350 \mathrm{~mL} \cdot \mathrm{ha}^{-1}$ \\
\hline Osthole EC $1.0 \%$ & cnidium lactone & Suke Agro-chemical of Jiangsu Province Co., Ltd. & $3000 \mathrm{~g} \cdot \mathrm{ha}^{-1}$ \\
\hline Pyrethrin SC $1.5 \%$ & pyrethrin & Beijing Kingbo Biotech Co., Ltd. & $2400 \mathrm{~mL} \cdot \mathrm{ha}^{-1}$ \\
\hline Rotenone SC 7.5\% & rotenone & Beijing Kingbo Biotech Co., Ltd. & $975 \mathrm{~mL} \cdot \mathrm{ha}^{-1}$ \\
\hline \multicolumn{4}{|l|}{ Insect growth regulator } \\
\hline Chlorbenzuron SC 25\% & chlorbenzuron & HONOR-BIO & $150 \mathrm{mg} \cdot \mathrm{kg}^{-1}$ \\
\hline Diflubenzuron SC 20\% & diflubenzuron & Anlin Biochemical Co., Ltd. & $133 \mathrm{mg} \cdot \mathrm{L}^{-1}$ \\
\hline Flufenoxuron SC 2.5\% & flufenoxuron & BASF & $750 \mathrm{~mL} \cdot \mathrm{ha}^{-1}$ \\
\hline Hexanumuron SC 5\% & hexanumuron & $\begin{array}{l}\text { Jiukang Biological Science and Technology } \\
\text { Development Co., Ltd. }\end{array}$ & $120 \mathrm{~g} \cdot \mathrm{ha}^{-1}$ \\
\hline
\end{tabular}

${ }^{1}$ EC, emulsifiable concentrate; GR, granules; SC, suspension concentrate; WG, water-dispersible granules.

\subsubsection{Effect of Insecticides on EPN Survival}

Insecticides were diluted and added to each $9 \mathrm{~cm}$ Petri dish, with each dish containing 1000 IJs in $10 \mathrm{~mL}$ to a final concentration corresponding to the recommended field concentration (RC) and 1/10 RC. Infective juveniles in water were used as controls. Each treatment had three replicates (dishes). The Petri dishes were incubated at $25 \pm 1{ }^{\circ} \mathrm{C}$ in the dark for $24 \mathrm{~h}$. Three $100 \mu \mathrm{L}$ samples were then drawn from each dish and mortality of the IJs was calculated. Infective juveniles were considered dead when they showed no response after probing with a needle [26].

\subsubsection{Effect of Insecticides on EPN Infectivity}

The nematode suspension in $1.5 \mathrm{~mL}$ containing 500 live IJs were added into a $9 \mathrm{~cm}$ Petri dish lined with two layers of $9 \mathrm{~cm}$ filter paper (Xinhua, China). Ten ninth to 11th T. molitor larvae (body lengths $2-3 \mathrm{~cm}$ ) were then placed in each dish [26]. Treatments contained EPN alone, EPN-insecticide combinations and insecticide dilutions at the respective concentrations (as described above). Water treatment was used as control. Each treatment had three replicates (dishes). The dishes were sealed with Parafilm and incubated at $25 \pm 1{ }^{\circ} \mathrm{C}, 70 \% \mathrm{RH}$ for $72 \mathrm{~h}$. Mortality of the T. molitor larvae was checked. Dead larvae were incubated in clean Petri dishes and dissected three days later to estimate the rate of infection by EPN [9].

\subsubsection{Virulence of EPN-Insecticide Combinations against B. odoriphaga}

One $2 \mathrm{~cm}$ length stem of chive was put into each $9 \mathrm{~cm}$ Petri dish furnished with two layers of 9 $\mathrm{cm}$ filter paper. Nematodes were treated with the selected insecticides and adjusted to $250 \mathrm{IJ} \cdot \mathrm{mL}^{-1}$. 
Suspensions of $1 \mathrm{~mL}$ of insecticide at 1/10 RC, EPN-insecticide (1/10 RC) combination, or EPN were added to each dish. Ten $B$. odoriphaga larvae at fourth instar were gently placed on the filter paper by a brush. Water treatment was used as the control. Each treatment had three replicates (dishes). The dishes were sealed with Parafilm and incubated at $25 \pm 1{ }^{\circ} \mathrm{C}$ for $72 \mathrm{~h}$. The mortality of the B. odoriphaga larvae was checked every $24 \mathrm{~h}$. Dead larvae were incubated in clean Petri dishes at $25 \pm 1{ }^{\circ} \mathrm{C}, 70 \%$ relative humidity (RH), and dissected two days later, to estimate the rate of infection by EPN [3].

\subsubsection{Effect of Temperature on the Virulence of EPN-Imidacloprid Combinations against B. odoriphaga}

Insecticides that showed potential synergistic effects on EPN were used to further test the effects of temperature on the virulence of the EPN-insecticide combinations against the B. odoriphaga larvae. The method was the same as described above [3]; besides that, the dishes were incubated at $15 \pm 1$, $20 \pm 1$ and $25 \pm 1{ }^{\circ} \mathrm{C}$ for $72 \mathrm{~h}$.

\subsection{Field Experiment}

Two experiments were conducted in chive fields that was naturally infested with B. odoriphaga in 2016-2017, in Zhangqiu, Jinan City and in Weifang City in Shandong Province, China. Soil samples were baited with T. molitor, using the method described previously by Liu et al. [31], and no native EPN populations were recovered from the experimental field. Larval populations of the chive gnat were estimated one day before the field experiment. Five soil samples $\left(0.08 \mathrm{~m}^{2}\right.$, depth $\left.=20 \mathrm{~cm}\right)$ containing the chive plants were individually taken from the experimental field, and the number of the larval and pupal stages of $B$. odoriphaga in the soil and on the plants was counted. The population of the B. odoriphaga larvae was expressed as number of larvae $\mathrm{m}^{-2}$. In both experiments, the plant density was 36 plants $\cdot \mathrm{m}^{-2}$. Imidacloprid were applied at $4.5 \mathrm{~g} \cdot \mathrm{ha}^{-1}$, together with $\mathrm{H}$. indica LN2 at $3.0 \times 10^{9} \mathrm{IJ} \cdot \mathrm{ha}^{-1}$ $(\mathrm{LN} 2+\mathrm{IMI})$, S. feltiae SN at $3.0 \times 10^{9} \mathrm{IJ} \cdot \mathrm{ha}^{-1}(\mathrm{SN}+\mathrm{IMI})$, or H. indica LN2 and S. feltiae SN both at $1.5 \times 10^{9} \mathrm{IJ} \cdot \mathrm{ha}^{-1}$ (LN2 + SN + IMI). Water without nematodes or insecticides was used as the negative control. Each treatment had five replicates (plots) arranged in a randomized complete block design. The application of nematodes was done on cloudy days or after 4:00 pm, to avoid strong UV radiation.

The first experiment was conducted at Baijia Village in Zhangqiu on 8 October, 2016. Experimental plot was $148 \mathrm{~m}^{2}(74 \mathrm{~m} \times 2 \mathrm{~m})$, with a $0.6 \mathrm{~m}$ buffer space between plots. The density of the chive gnats in the field was $277.50 \pm 29.42$ larvae $\cdot \mathrm{m}^{-2}$. Chlorbenzuron was applied at RC as the positive control. Nematode and insecticide suspensions were applied by using the irrigation system (with nozzle size of $6.5 \mathrm{~mm}$ in diameter). All treatments were applied three times on the date of the experiment, 27 March and 23 September 2017. Chlorbenzuron was applied one extra time, on 17 December, 2016. Chive was harvested on 17 December 2016 and 3 January, 2017. Imidacloprid were also applied at RC, but it showed no difference to the control on the suppression of the chive gnat in the first 1.5 months, so no further survey was conducted on the plots treated with imidacloprid.

The second experiment was conducted at Daotian Town in Weifang on 24 October, 2016. The experimental plot was $74 \mathrm{~m}^{2}(37 \mathrm{~m} \times 2 \mathrm{~m})$, with a $0.6 \mathrm{~m}$ buffer space between the plots. The density of chive gnats in the field was $283.75 \pm 36.58$ larvae $\cdot \mathrm{m}^{-2}$. Phoxim (Shengbang Lunan Pesticide Co., Ltd. of Shandong, recommended field rate $1125 \mathrm{~mL} \cdot \mathrm{ha}^{-1}$ ) was applied at RC as the positive control. Nematode and insecticide suspensions were applied by using a sprayer with a flat-fan nozzle at $206 \mathrm{kPa}$ (with nozzle size of $6.5 \mathrm{~mm}$ in diameter), without a screen. All treatments were applied twice on the date of the experiment, and on 30 September, 2017. Phoxim was applied twice more, on 23 December, 2016, and 9 February, 2017. The chives were harvested on 23 December, 2016, and 23 January and 28 February, 2017.

A field survey was conducted every 10 or 20 days until 360 days after the first application, based on the dynamics of $B$. odoriphaga in the field. Five chive plants were sampled from each plot as described above, to estimate the number of larvae and pupae from each sample. All of the fresh chive plants harvested from each plot were weighed, and the yields of chive were calculated as $\mathrm{kg} \cdot \mathrm{m}^{-2}$. 


\subsection{Cost Estimation of EPN-Imidacloprid Applications}

The costs for B. odoriphaga control in chive production were estimated based on the retail prices of the EPN and the insecticides in October 2017. The average chive yield was calculated as $\mathrm{kg} \cdot \mathrm{ha}^{-1}$. The costs for different treatments were estimated. The net profit was estimated based on the average price of chives at three harvest times, and the cost per ha from the different treatments [15].

\subsection{Statistical Analysis}

Mortality rates of B. odoriphaga and T. molitor were corrected by control mortality using Abbott's formula [32]. Percentage data were arcsine square root-transformed prior to statistical analysis performed with SPSS 16.0 software (SPSS Inc., Chicago, IL, USA). Means were separated using Tukey's test. Differences among the means were considered significant at $p<0.05$. Synergistic, additive, or antagonistic interactions between the agents in the combination treatments were determined by using a $\chi^{2}$ test with the control-corrected data [15].

\section{Results}

\subsection{Effect of Insecticides on EPN Survival}

The mortality rates of S. feltiae SN and H. indica LN2 exposed to two concentrations of the tested insecticides are shown in Figure 1. No significant differences in the mortality rate were found among the different insecticide treatments and the control, for both EPN isolates $(\mathrm{F} \leq 1.171, \mathrm{df}=14,30$, $p \geq 0.345)$. The mortality rates of the two EPN isolates after treatment with 14 insecticides at RC and $1 / 10$ RC were $<2 \%$. All the insecticides were used to test their effects on EPN infectivity.

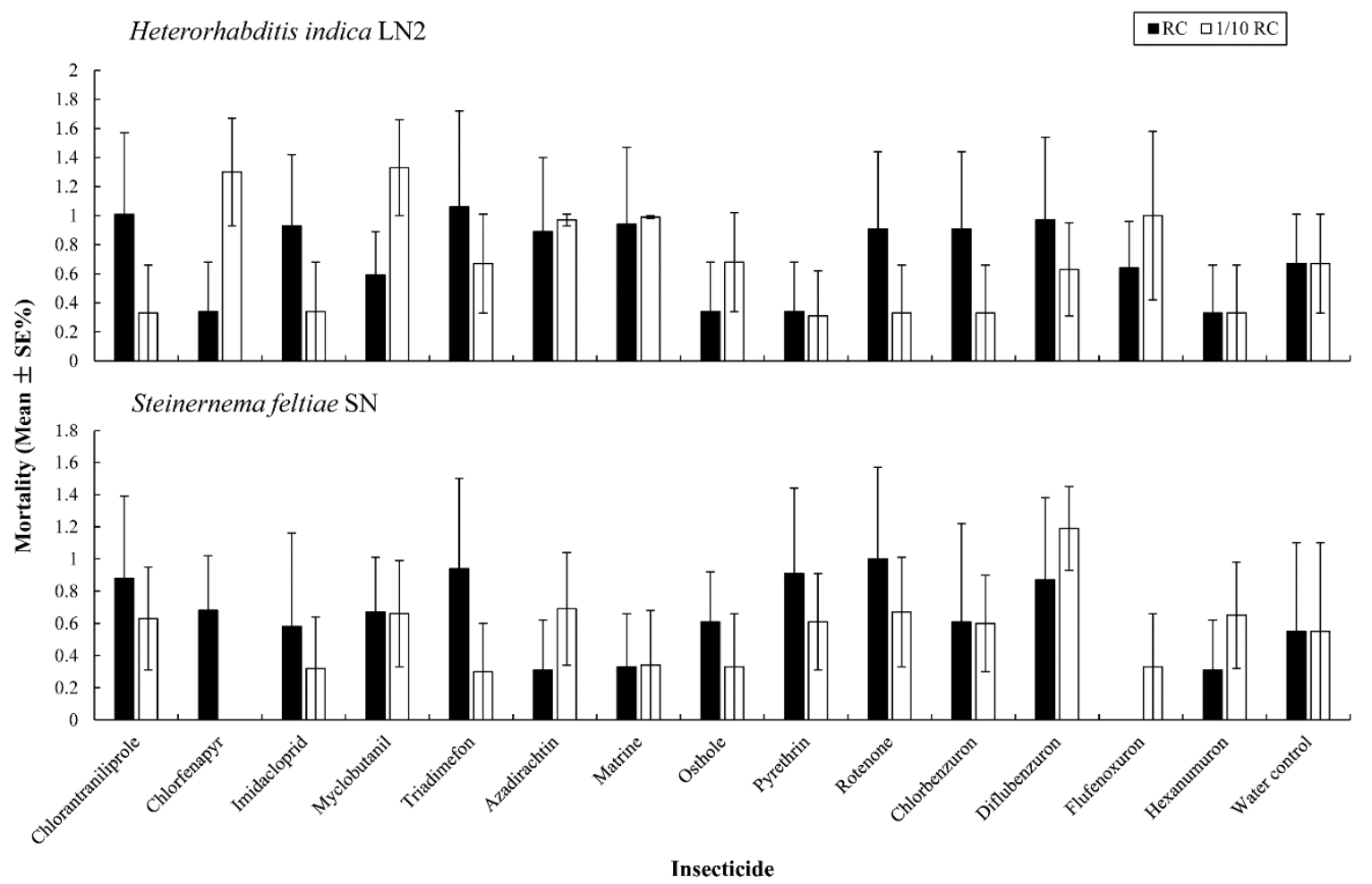

Figure 1. Mortality rates of Steinernema feltiae SN and Heterorhabditis indica LN2, $72 \mathrm{~h}$ after exposure to different insecticides at the recommended field concentration (RC) and 1/10 RC. The bars do not differ significantly at the same insecticide concentration $(p>0.05$, Tukey's test). 


\subsection{Effect of Insecticides on EPN Infectivity}

The corrected mortality rates of the T. molitor larvae exposed to S. feltiae SN and H. indica LN2 treated by two concentrations of different insecticides are shown in Figure 2. The corrected mortality rates for the larvae caused by EPN and treated with different insecticides differed significantly, but no significant difference was found between the corrected mortality rates of the larvae as caused by insecticide-treated and untreated nematodes, for each insecticide $(\mathrm{F} \geq 2.412, \mathrm{df}=14,30, p \leq 0.021)$. The corrected mortality rates of the larvae treated by $S$. feltiae SN ranged from $53.33 \pm 3.33 \%$ to $96.67 \pm 3.33 \%$, and from $40.00 \pm 5.77 \%$ to $93.33 \pm 6.67 \%$ by $H$. indica LN2. Both S. feltiae SN and H. indica LN2 treated with imidacloprid caused the highest mortality of the T. molitor larvae when compared with the other insecticides at the same concentration.

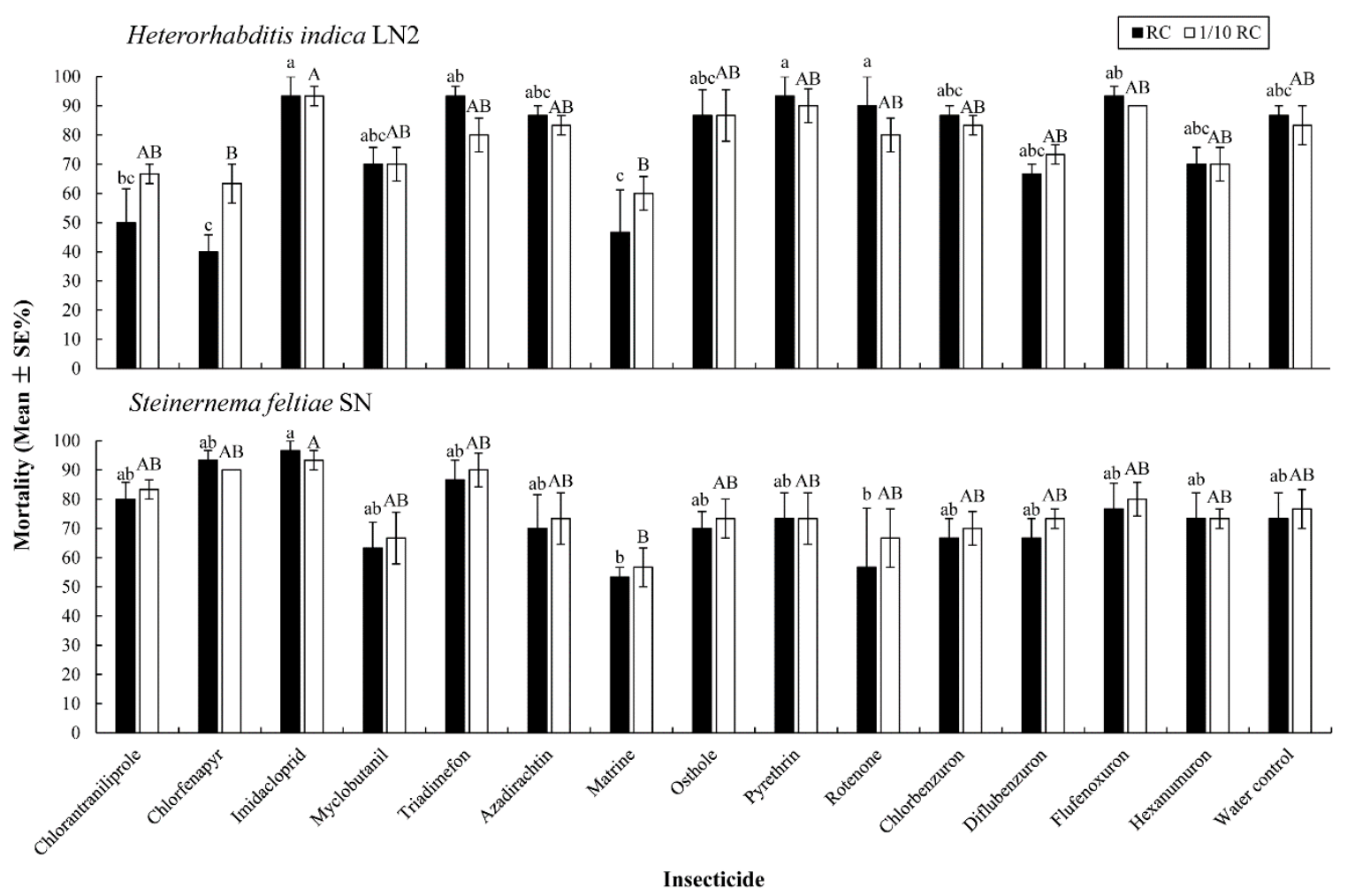

Figure 2. The corrected mortality rates of the Tenebrio molitor larvae, $72 \mathrm{~h}$ after exposure to Steinernema feltiae SN and Heterorhabditis indica LN2 in different insecticides, at the recommended field concentration $(\mathrm{RC})$ and 1/10 RC. Bars with different uppercase or lowercase letters indicate significant differences among the different insecticides for RC or $1 / 10 \mathrm{RC}$, respectively ( $p<0.05$, Tukey's test).

\subsection{Virulence of EPN-Insecticide Combinations against B. odoriphaga}

The corrected mortality rates of the B. odoriphaga larvae treated with EPN-insecticide combinations are shown in Table 2. Combinations of different insecticides with S. feltiae SN did not cause significant differences in the mortality rate of the B. odoriphaga larvae when compared with S. feltiae SN, after treating the larvae for $48 \mathrm{~h}$ and $72 \mathrm{~h}(\mathrm{~F}=3.090$ and $1.331, \mathrm{df}=14,30, p=0.005$ and 0.270 , respectively). However, at $24 \mathrm{~h}$, the combination of imidacloprid or osthole with $\mathrm{S}$. feltiae SN caused a $93.33 \pm 3.33 \%$ mortality rate in the $B$. odoriphaga larvae, which was significantly higher than that caused by $S$. feltiae $\mathrm{SN}(\mathrm{F}=6.376, \mathrm{df}=14,30, p<0.001)$. The $\chi^{2}$ test showed that synergistic interactions were observed for the imidacloprid-S. feltiae SN $\left(\chi^{2}=4.03\right)$ and osthole-S. feltiae SN $\left(\chi^{2}=4.57\right)$ combinations. Different insecticide- $H$. indica LN2 combinations did not cause significantly mortality of the B. odoriphaga larvae, when compared with $H$. indica $\mathrm{LN} 2$ at three tested times $(\mathrm{F} \leq 3.877, \mathrm{df}=14,30, p \geq 0.001)$. No synergistic interactions were observed for different insecticides with $H$. indica LN2 $\left(\chi^{2} \leq 1.822\right)$. 
Table 2. The corrected mortality rate $( \pm$ SE) of Bradysia odoriphaga larvae treated with different entomopathogenic nematode and insecticide combinations after 24,48 and $72 \mathrm{~h}$ exposure to Steinernema feltiae SN and Heterorhabditis indica LN2 in different insecticides at the diluted recommended field concentration (1/10 RC).

\begin{tabular}{|c|c|c|c|c|c|c|}
\hline \multirow{3}{*}{ Insecticide } & \multicolumn{6}{|c|}{ Corrected Mortality Rate (Mean \pm SE $\%)^{1}$} \\
\hline & \multicolumn{3}{|c|}{ Steinernema feltiae SN } & \multicolumn{3}{|c|}{ Heterorhabditis indica LN2 } \\
\hline & $24 \mathrm{~h}$ & $48 \mathrm{~h}$ & $72 \mathrm{~h}$ & $24 \mathrm{~h}$ & $48 \mathrm{~h}$ & $72 \mathrm{~h}$ \\
\hline Chlorantraniliprole & $66.67 \pm 3.33 \mathrm{bc}$ & $73.33 \pm 3.33 b$ & $96.67 \pm 3.33$ & $46.67 \pm 3.33 \mathrm{bc}$ & $73.33 \pm 3.33 b$ & $93.33 \pm 3.33$ \\
\hline Chlorfenapyr & $66.67 \pm 3.33 \mathrm{bc}$ & $76.67 \pm 3.33 \mathrm{ab}$ & $86.67 \pm 3.33$ & $53.33 \pm 8.82 \mathrm{abc}$ & $66.67 \pm 12.02 b$ & $83.33 \pm 3.33$ \\
\hline Imidacloprid & $93.33 \pm 3.33 \mathrm{a}$ & $96.67 \pm 3.33 \mathrm{a}$ & $100.00 \pm 0.00$ & $76.67 \pm 8.82 \mathrm{a}$ & $90.00 \pm 5.77 a$ & $100.00 \pm 0.00$ \\
\hline Myclobutanil & $76.67 \pm 6.67 \mathrm{abc}$ & $83.33 \pm 3.33 \mathrm{ab}$ & $93.33 \pm 3.33$ & $50.00 \pm 5.77 \mathrm{abc}$ & $80.00 \pm 5.77 \mathrm{ab}$ & $93.33 \pm 3.33$ \\
\hline Triadimefon & $70.00 \pm 5.77 \mathrm{bc}$ & $76.67 \pm 3.33 \mathrm{ab}$ & $90.00 \pm 5.77$ & $53.33 \pm 3.33 \mathrm{abc}$ & $76.67 \pm 6.67 \mathrm{ab}$ & $86.67 \pm 6.67$ \\
\hline Azadirachtin & $63.33 \pm 3.33 b c$ & $70.00 \pm 0.00 \mathrm{~b}$ & $93.33 \pm 3.33$ & $40.00 \pm 5.77 \mathrm{c}$ & $63.33 \pm 3.33 b$ & $86.67 \pm 8.82$ \\
\hline Matrine & $70.00 \pm 5.77 b c$ & $80.00 \pm 5.77 \mathrm{ab}$ & $80.00 \pm 5.77$ & $50.00 \pm 5.77 \mathrm{abc}$ & $76.67 \pm 3.33 \mathrm{ab}$ & $83.33 \pm 3.33$ \\
\hline Osthole & $93.33 \pm 3.33 \mathrm{a}$ & $93.33 \pm 3.33 \mathrm{ab}$ & $93.33 \pm 3.33$ & $56.67 \pm 3.33 \mathrm{abc}$ & $80.00 \pm 5.77 \mathrm{ab}$ & $93.33 \pm 3.33$ \\
\hline Pyrethrin & $76.67 \pm 3.33 \mathrm{abc}$ & $93.33 \pm 3.33 \mathrm{ab}$ & $93.33 \pm 3.33$ & $66.67 \pm 8.82 \mathrm{abc}$ & $80.00 \pm 5.77 \mathrm{ab}$ & $83.33 \pm 3.33$ \\
\hline Rotenone & $76.67 \pm 3.33 \mathrm{abc}$ & $90.00 \pm 5.77 \mathrm{ab}$ & $96.67 \pm 3.33$ & $40.00 \pm 0.00 \mathrm{c}$ & $60.00 \pm 5.77 b$ & $86.67 \pm 3.33$ \\
\hline Chlorbenzuron & $86.67 \pm 3.33 \mathrm{ab}$ & $86.67 \pm 3.33 \mathrm{ab}$ & $93.33 \pm 3.33$ & $40.00 \pm 5.77 \mathrm{c}$ & $60.00 \pm 5.77 b$ & $93.33 \pm 3.33$ \\
\hline Diflubenzuron & $76.67 \pm 6.67 \mathrm{abc}$ & $90.00 \pm 5.77 \mathrm{ab}$ & $96.67 \pm 3.33$ & $56.67 \pm 8.82 \mathrm{abc}$ & $73.33 \pm 3.33 b$ & $86.67 \pm 3.33$ \\
\hline Flufenoxuron & $73.33 \pm 3.33 \mathrm{abc}$ & $83.33 \pm 3.33 \mathrm{ab}$ & $90.00 \pm 0.00$ & $76.67 \pm 3.33 \mathrm{ab}$ & $76.67 \pm 3.33 \mathrm{ab}$ & $93.33 \pm 3.33$ \\
\hline Hexanumuron & $90.00 \pm 0.00 \mathrm{ab}$ & $90.00 \pm 0.00 \mathrm{ab}$ & $93.33 \pm 3.33$ & $56.67 \pm 3.33 \mathrm{abc}$ & $76.67 \pm 8.82 \mathrm{ab}$ & $90.00 \pm 5.77$ \\
\hline EPN control & $50.00 \pm 5.77 c$ & $86.67 \pm 3.33 \mathrm{ab}$ & $93.33 \pm 3.33$ & $50.00 \pm 5.77 \mathrm{abc}$ & $70.00 \pm 5.77 b$ & $90.00 \pm 0.00$ \\
\hline
\end{tabular}

${ }^{1}$ Means within a column followed by different letters are significantly different ( $p<0.05$, Tukey's test). 


\subsection{Effect of Temperature on the Virulence of EPN-Imidacloprid Combinations against $\mathrm{B}$. odoriphaga}

Corrected mortality rates of the B. odoriphaga larvae treated with imidacloprid-EPN combinations at different temperatures are shown in Figure 3. At a low temperature of $15^{\circ} \mathrm{C}$, treatments of $H$. indica LN2 and H. indica LN2-imidacloprid did not cause the death of the B. odoriphaga larvae. Treatments containing $S$. feltiae SN caused significantly higher corrected mortality rates of the B. odoriphaga larvae $(\mathrm{F} \geq 88.893, \mathrm{df}=4,10, p<0.001)$, which were $>93.33 \%$ after $72 \mathrm{~h}$. Treatments of $H$. indica LN2 and $H$. indica LN2-imidacloprid showed poor virulence against the B. odoriphaga larvae at $20^{\circ} \mathrm{C}$, with the corrected mortality rates of the $B$. odoriphaga larvae being significantly lower than those in treatments containing $S$. feltiae $\mathrm{SN}$ at three checking times $(\mathrm{F} \geq 16.631, \mathrm{df}=4,10, p<0.001)$. The corrected mortality rates of the $B$. odoriphaga larvae caused by treatments containing $S$. feltiae SN were $>90.00 \%$ after $48 \mathrm{~h}$. The corrected mortality rates of the B. odoriphaga larvae caused by $H$. indica LN2 and $H$. indica LN2-imidacloprid increased at $25^{\circ} \mathrm{C}$, but they was still significantly lower after $24 \mathrm{~h}$ and $48 \mathrm{~h}(\mathrm{~F} \geq 5.027$, $\mathrm{df}=4,10, p \leq 0.018)$. The corrected mortality rates of the $B$. odoriphaga larvae were all $>90.00 \%$ after $72 \mathrm{~h}$ at $25^{\circ} \mathrm{C}$.

$15^{\circ} \mathrm{C}$

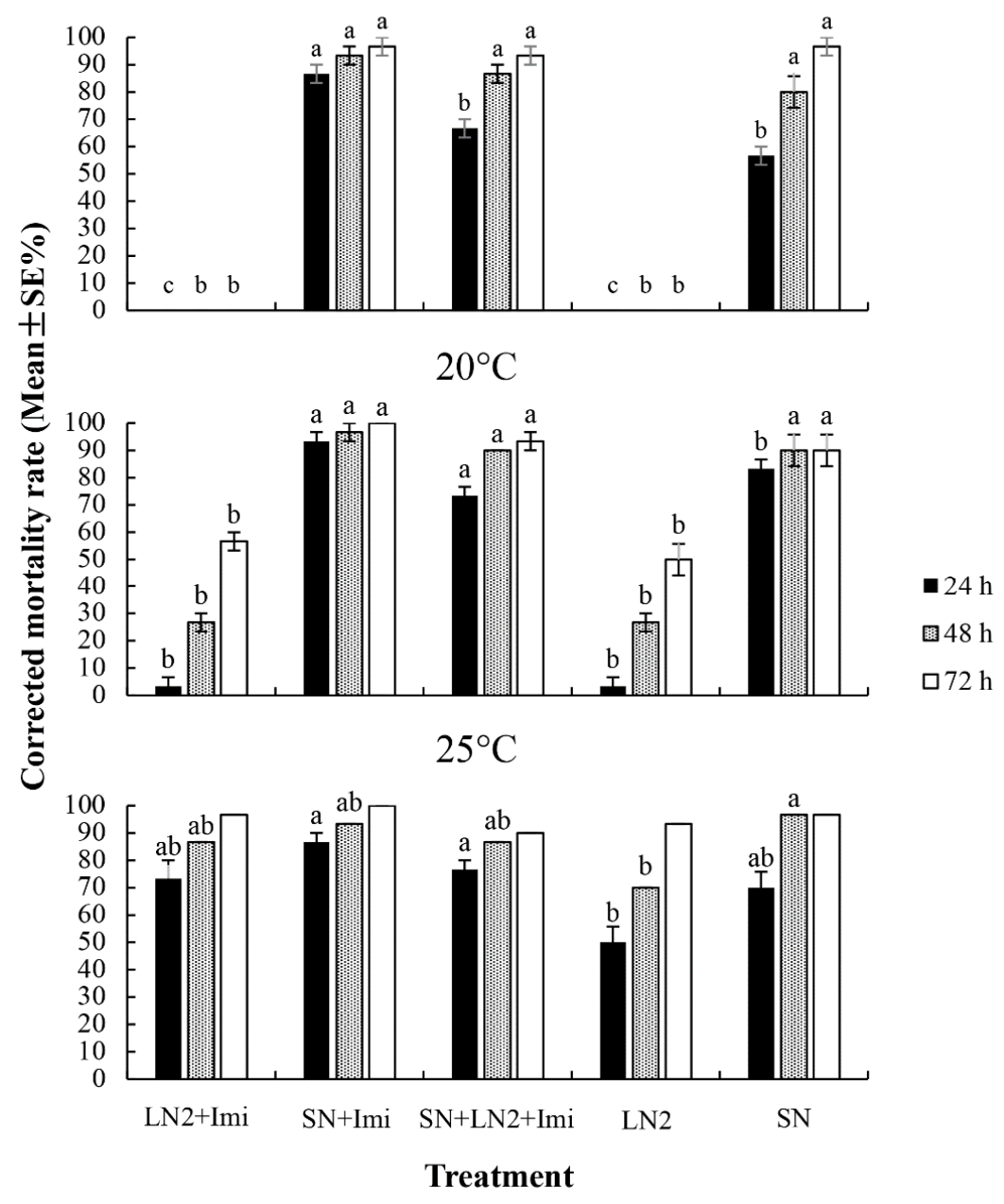

Figure 3. The corrected mortality rates of the Bradysia odoriphaga larvae treated with entomopathogenic nematodes (EPN) and EPN-imidacloprid combinations for 24, 48, and $72 \mathrm{~h}$. LN2: Heterorhabditis indica LN2 applied at $3.0 \times 10^{9} \mathrm{IJ} \cdot \mathrm{ha}^{-1}$; SN: Steinernema feltiae $\mathrm{SN}$ applied at $3.0 \times 10^{9} \mathrm{IJ} \cdot \mathrm{ha}^{-1}$; Imi: imidacloprid at $1 / 10$ recommended field rate $\left(4.5 \mathrm{~g} \cdot \mathrm{ha}^{-1}\right) ; \mathrm{SN}+\mathrm{LN} 2$ : both $H$. indica LN2 and S. feltiae SN applied at $1.5 \times 10^{9} \mathrm{IJ} \cdot \mathrm{ha}^{-1}$. Bars with the same letter do not differ significantly at the same checking time $(p<0.05$, Tukey's test). 


\subsection{Effects of EPN-Imidacloprid Applications on a B. odoriphaga Larval Population in the Field}

Larval populations of $B$. odoriphaga in the field during the experimental period are shown in Figure 4. In the experiment conducted in Zhangqiu, larval populations in the plots with treatments containing S. feltiae SN or chlorbenzuron decreased over time during the first 60 days, and they were significantly lower than those in the plots treated with $H$. indica LN2-imidacloprid or water ( $\mathrm{F} \geq 6.405, \mathrm{df}=4,20, p<0.001)$. Larval population in the plots treated with chlorbenzuron increased significantly at 70 days when compared with the treatments containing S. feltiae $\mathrm{SN}(\mathrm{F}=17.876, \mathrm{df}=4$, $20, p<0.001)$. One more application of chlorbenzuron at $\mathrm{RC}$ was performed to protect the chives. The larval population decreased again until 110 days, but it then increased again in the plots treated with chlorbenzuron to the same level as in the water control. Larval populations in the plots with treatments containing S. feltiae SN remained significantly lower than those in the other plots $(\mathrm{F}=23.711, \mathrm{df}=4,20$, $p<0.001)$. Protective films used to cover the plants were removed at 120 days, and the larvae had hardly recovered from the soil because of the cold weather. Larval populations increased later on, with the increasing temperature, so a re-application of all treatments were conducted on $27 \mathrm{March}$, 2017. After the second application of all treatments, larval populations in the plots with treatments containing $S$. feltiae SN or chlorbenzuron were significantly lower than those with other treatments ( $\mathrm{F} \geq 12.863, \mathrm{df}=4,20, p<0.001)$. By late May, the high temperature had resulted in a lower larval population in the field. The larval population increased again when the temperature decreased in October. The reapplication of all treatments was required to protect the chive production for next year at this time. The highest larval population recorded in the field was 52.97 larvae $\cdot \mathrm{m}^{-2}$ after treatment, but this was 27.39 larvae $\cdot \mathrm{m}^{-2}$ in the plots with treatments containing S. feltiae SN.

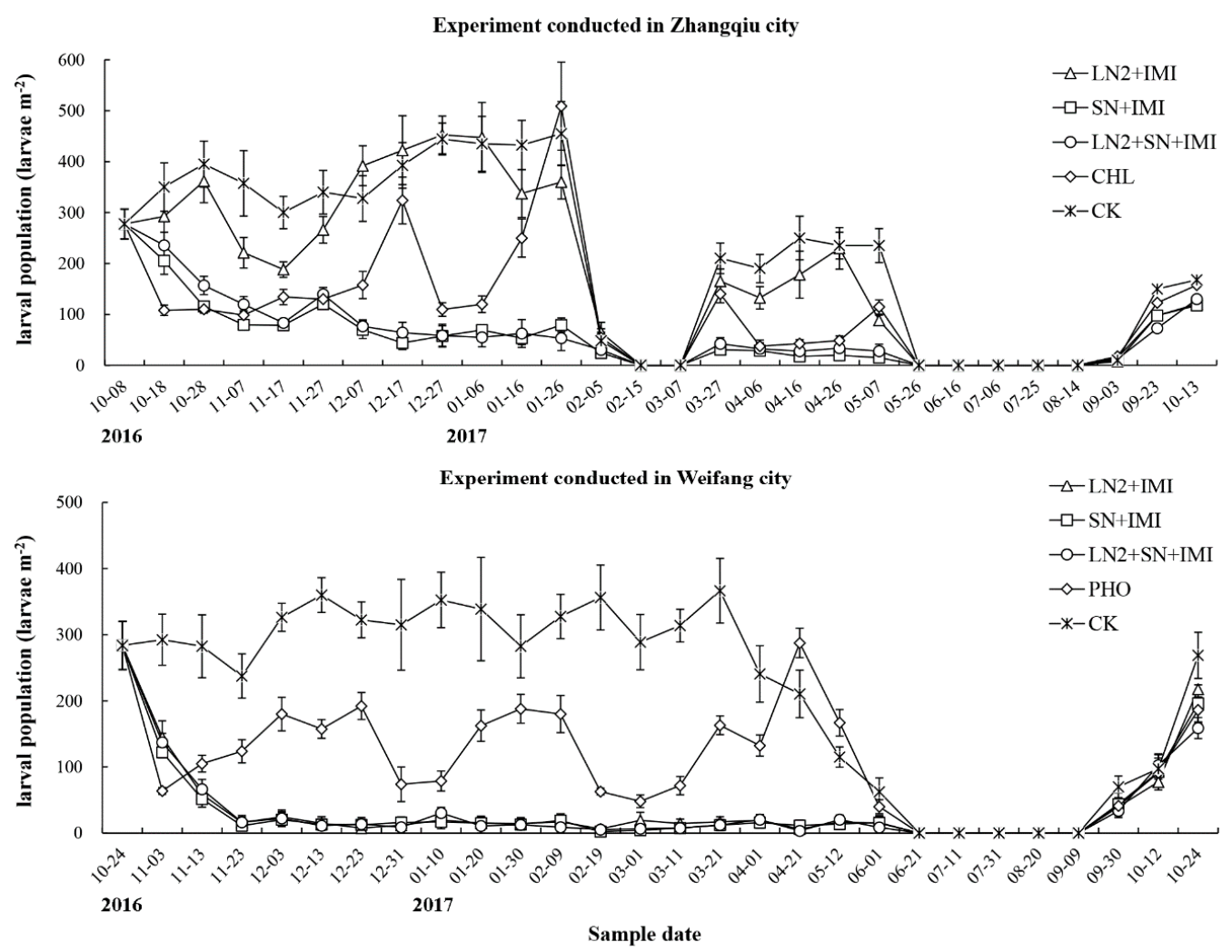

Figure 4. The larval population of Bradysia odoriphaga recovered from field surveys in the experiments conducted in Zhangqiu and Weifang city in China, in 2016-2017. LN2: Heterorhabditis indica LN2 applied at $3.0 \times 10^{9} \mathrm{IJ} \cdot \mathrm{ha}^{-1}$; SN: Steinernema feltiae $\mathrm{SN}$ applied at $3.0 \times 10^{9} \mathrm{IJ} \cdot \mathrm{ha}^{-1}$; Imi: imidacloprid at $1 / 10$ recommended field rate $\left(4.5 \mathrm{~g} \cdot \mathrm{ha}^{-1}\right) ; \mathrm{SN}+\mathrm{LN} 2$ : both $H$. indica LN2 and S. feltiae SN applied at $1.5 \times 10^{9} \mathrm{IJ} \cdot \mathrm{ha}^{-1}$; CHL: chlorbenzuron applied at the recommended field rate of $15 \mathrm{mg} \cdot \mathrm{kg}^{-1}$; PHO: phoxim applied at the recommended field rate of $1125 \mathrm{~mL} \cdot \mathrm{ha} ; \mathrm{CK}$, water control. 
In the experiment conducted in Weifang, the dynamics of the larval population of B. odoriphaga in the field were similar to those in the experiment conducted in Zhangqiu. However, no obvious decrease of the larvae in the field was observed in February, 2017. Chives were planted under the protective film in a green house (so-called double-sheds). The temperature could be maintained in the green house after the removal of the inner protective film after the third harvest of chives, which led to a continously high larval population in the control. EPN-imidacloprid combinations sucessfully suppressed the larval population in this field. Larval populations were significantly lower in the plots with EPN-imidacloprid treatments than those with phoxim or water at most sample times (F $\geq 21.859$, $\mathrm{df}=4,20, p<0.001)$. No significant differences in larval populations was found among plots with phoxim and EPN-imidacloprid treatments at sample times shortly after phoxim application, and the larval populations in the plots with these treatments were significantly higher than those with water $(\mathrm{F} \geq 3.146, \mathrm{df}=4,20, p<0.05)$. No significant differences in larval populations were found in the plots with different treatments from June to October 2017 ( $\mathrm{F} \leq 1.097, \mathrm{df}=4,20, p \geq 0.385)$. The highest larval population recorded in the control plots was 78.71 larvae $\cdot \mathrm{m}^{-2}$, and 24.88 larvae $\cdot \mathrm{m}^{-2}$ in plots with EPN-imidaclprid treatments.

\subsection{Effects of EPN-Imidacloprid Applications on Chive Yields}

Chive weights from different treatments in the two experiments are shown in Figure 5. In the experiment conducted in Zhangqiu, chive yields in the plots with treatments containing $S$. feltiae or chlorbenzuron were $>3.55 \mathrm{~kg} \cdot \mathrm{m}^{-2}$, which were significantly higher than that in the plots treated with H. indica LN2-imidacloprid $\left(2.88 \mathrm{~kg} \cdot \mathrm{m}^{-2}\right)$ or water $\left(2.68 \mathrm{~kg} \cdot \mathrm{m}^{-2}\right)(\mathrm{F}=25.383, \mathrm{df}=4,20, p<0.001)$. In the experiment conducted in Weifang, average yields of chive in the plots with EPN-imidacloprid treatments or phoxim were 4.25 to $4.56 \mathrm{~kg} \cdot \mathrm{m}^{-2}$, which were significantly higher than that with water $\left(2.44 \mathrm{~kg} \cdot \mathrm{m}^{-2}\right)(\mathrm{F}=89.006, \mathrm{df}=4,20, p<0.001)$. The average yields of chive harvested from the treated plots in the experiment conducted in Weifang were higher than that in Zhangqiu, although the yields in the control plots were higher in Zhangqiu than in Weifang.

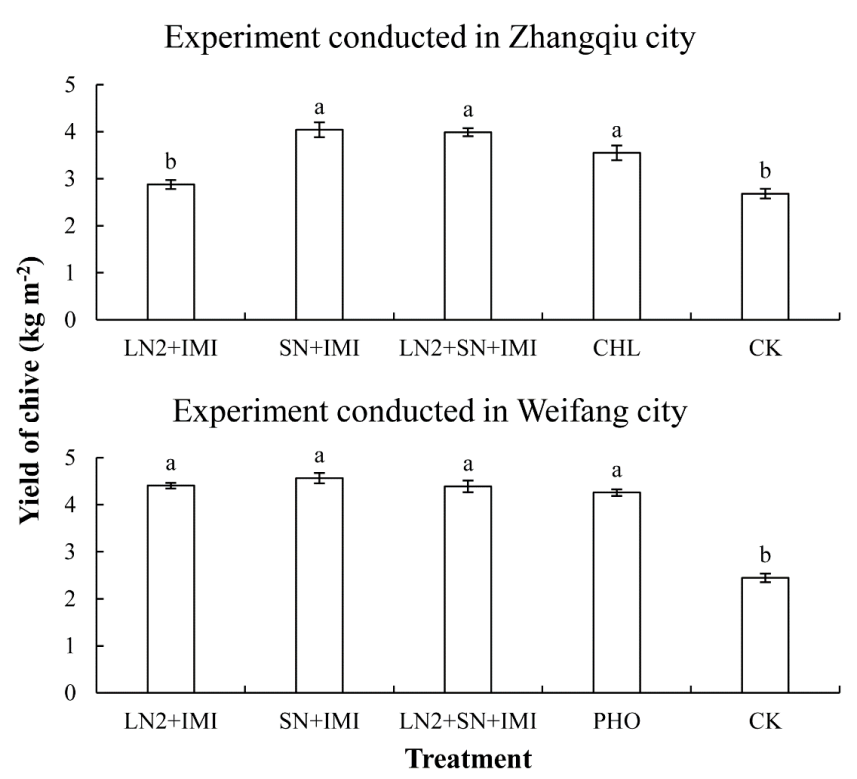

Figure 5. Average yields of chive in the plots with different treatments in the experiments conducted in Zhangqiu and Weifang city in China, in 2016-2017. LN2: Heterorhabditis indica LN2 applied at $3.0 \times 10^{9} \mathrm{IJ} \cdot \mathrm{ha}^{-1}$; SN: Steinernema feltiae SN applied at $3.0 \times 10^{9} \mathrm{IJ} \cdot \mathrm{ha}^{-1}$; Imi: imidacloprid at 1/10 recommended field rate $\left(4.5 \mathrm{~g} \cdot \mathrm{ha}^{-1}\right)$; SN + LN2: both $H$. indica LN2 and S. feltiae SN applied at $1.5 \times 10^{9} \mathrm{IJ} \cdot \mathrm{ha}^{-1}$; CHL: chlorbenzuron applied at the recommended field rate of $15 \mathrm{mg} \cdot \mathrm{kg}^{-1}$; PHO: phoxim applied at the recommended field rate of $1125 \mathrm{~mL} \cdot \mathrm{ha}^{-1} ; \mathrm{CK}$, water control. Bars with the same letter do not differ significantly ( $p<0.05$, Tukey's test). 


\subsection{Cost Estimation of the Integrated Management Strategy}

The cost, yield of chive, and the income of the farmers by using EPN-imidacloprid and chemicals in one hectare for B. odoriphaga control in chive production were calculated and shown in Table 3. In the experiment conducted in Zhangqiu, the profit was the highest in the field treated with $S$. feltiae SN-imidacloprid and H. indica LN2-S. feltiae SN-imidacloprid, because the chive price was higher from EPN-treated fields than chlorbenzuron-treated field. In the experiment conducted in Weifang, the profit was similar for different treatments except for the water control, because the chive price was the same from field with different treatments.

Table 3. The cost and benefit for the chive gnat control by EPN-imidacloprid combinations and chemicals in chive production in the year 2016-2017.

\begin{tabular}{|c|c|c|c|c|c|c|c|}
\hline Treatment ${ }^{1}$ & $\begin{array}{c}\text { EPN Rate } \\
\left(\times 10^{9}\right. \\
\left.\text { IJ } \cdot \mathbf{h a}^{-1}\right)\end{array}$ & $\begin{array}{l}\text { Imidacloprid } \\
\text { Rate }\end{array}$ & $\begin{array}{c}\text { Cost }^{2} \\
\left(\mathrm{CNY} \cdot \mathrm{ha}^{-1}\right)\end{array}$ & $\begin{array}{l}\text { Chive Yield } \\
\left(\mathrm{kg} \cdot \mathrm{ha}^{-1}\right)\end{array}$ & $\begin{array}{l}\text { Chive Price } \\
\left(\mathrm{CNY} \cdot \mathrm{kg}^{-1}\right)\end{array}$ & $\begin{array}{c}\text { Income } \\
\left(\mathrm{CNY} \cdot \mathrm{ha}^{-1}\right)\end{array}$ & $\begin{array}{c}\text { Profit } \\
\left(\mathrm{CNY} \cdot \mathrm{ha}^{-1}\right)\end{array}$ \\
\hline \multicolumn{8}{|c|}{ Experiment conducted in Zhangqiu city } \\
\hline LN2-imidacloprid & 9 & $3 \times 1 / 10 \mathrm{RC}$ & 5409 & 28,814 & 12 & 345,773 & 340,364 \\
\hline SN-imidacloprid & 9 & $3 \times 1 / 10 \mathrm{RC}$ & 9009 & 40,420 & 12 & 485,042 & 476,033 \\
\hline $\mathrm{LN} 2+\mathrm{SN}+$ imidacloprid & $4.5+4.5$ & $3 \times 1 / 10 \mathrm{RC}$ & 7209 & 39,920 & 12 & 479,039 & 471,830 \\
\hline chlorbenzuron & 0 & $4 \times 1 \mathrm{RC}$ & 2520 & 35,518 & 5.6 & 198,900 & 196,379 \\
\hline Control & 0 & 0 & 0 & 26,813 & 12 & 321,761 & 321,761 \\
\hline \multicolumn{8}{|c|}{ Experiment conducted in Weifang city } \\
\hline LN2-imidacloprid & 6 & $2 \times 1 / 10 \mathrm{RC}$ & 3606 & 44,022 & 3.8 & 167,284 & 163,678 \\
\hline SN-imidacloprid & 6 & $2 \times 1 / 10 \mathrm{RC}$ & 6006 & 45,623 & 3.8 & 173,367 & 167,361 \\
\hline $\mathrm{LN} 2+\mathrm{SN}+$ imidacloprid & $3+3$ & $2 \times 1 / 10 \mathrm{RC}$ & 4806 & 43,922 & 3.8 & 166,903 & 162,097 \\
\hline Phoxim & 0 & $4 \times 1 \mathrm{RC}$ & 1920 & 42,621 & 3.8 & 161,961 & 160,041 \\
\hline Control & 0 & 0 & 0 & 24,412 & 3.8 & 92,766 & 92,766 \\
\hline
\end{tabular}

${ }^{1}$ LN2: Heterorhabditis indica; SN: Steinernema feltiae. ${ }^{2}$ Data were calculated based on the prices of EPN, insecticides, and chive in October 2017.

\section{Discussion}

Evaluating the compatibility of EPN with different insecticides, and screening additive or synergistic insecticides for EPN provide the basis for the integrated management of target pests by using EPN with insecticides in the field. The co-application of EPN with insecticides can increase the control efficacy against a target pest, and reduce the cost of EPN applications and the dependence on chemical insecticides, thus contributing to slowing down the development of insecticide resistance and preventing adverse effects on human beings and the environment $[9,15]$. Fourteen insecticides tested in the present study were all compatible with S. feltiae SN and H. indica LN2, and had no adverse effect on the infectivity of the two EPN isolates against T. molitor larvae. The results suggested that the tested insecticides could be co-applied with S. feltiae SN and H. indica LN2. Steinernema feltiae was compatible with the azadirachtin product tested in this study, and it was reported to be compatible with some but not all formulations of azadirachtin [18,22]. The difference among different studies may be related to different formulations of the tested compounds and the experimental design [26]. As very few studies were reported on the compatibility of $H$. indica $\mathrm{LN} 2$ with insecticides, our results provided a reference for the combined use of $H$. indica LN2 with different insecticides.

In the experiment testing the effect of insecticides on EPN infectivity, imidacloprid was found to enhance the infectivity of S. feltiae SN and H. indica LN2 against T. molitor larvae. Results of the bioassay on B. odoriphaga further confirmed the synergistic effect of imidacloprid with S. feltiae SN. Imidacloprid belongs to a neonicotinoid, and it is a systemic insecticide that acts as an insect neurotoxin. Imidacloprid was widely used in pest control because of its high efficacy, relatively low vertebrae toxicity, low application rates, and long systemic persistence [21]. Imidacloprid was reported to interact synergistically with $H$. bacteriophora, $H$. megidis, $H$. marclatus, S. glaseri, and S. feltiae against different species of white grub $[21,33,34]$ and sweet potato whitefly [17]. Synergistic interactions were not found between $H$. indica LN2 and imidacloprid against B. odoriphaga in this study. Koppenhöfer et al. also found only additive effects of imidacloprid with S. kushidai against white grubs [35]. The major factor 
that is responsible for synergistic interactions between imidacloprid and EPN appears to be the general disruption of normal nerve function due to imidacloprid, which resulting in drastically reduced activity by the grubs. This sluggishness facilitates host attachment of the nematodes. Grooming and evasive behavior in response to nematode attack was also reduced in imidacloprid-treated grubs [35]. Osthole is a botanical insecticide that showed toxicity to the third instar larvae of B. odoriphaga [36]. Although osthole also showed synergistic interactions with $S$. feltiae $\mathrm{SN}$ against B. odoriphaga, it was not used for the field experiment, considering the cost of its application. The cost of a one-time application of osthole is three times as much as that of imidacloprid. Using imidacloprid as a synergist to EPN helps with a cost-effective method to control the chive gnat to be developed.

The mortality rates of B. odoriphaga larvae treated by the two EPN isolates in the study were $\geq$ $90 \%$, which suggested that the EPN products from solid cultures were as active as the nematodes from in vivo cultures used by Ma et al. [3]. However, for the same EPN isolates from another producer, the mortality rates of $B$. odoriphaga larvae were $\leq 50 \%$, even when the IJ were applied at high concentrations of 200 IJ.larvae ${ }^{-1}$ [28]. The difference in pathogenicity of the same EPN isolate from different production companies probably is due to the IJ quality [37]. The stability of the nematodes would be impacted during shipping and storage [38]. It is important to ensure that the EPN products are still at a high quality when the end users receive and apply them. This is the guarantee for the effective control of pests by EPN and other live biological control agents.

Temperature plays an important role in the motility, infectivity, development, and survival of EPN [39]. Infective juveniles of EPN slow down their movement and metabolism at low temperatures, which will affect their infectivity against the target host [40]. Bradysia odoriphaga can survival at low temperatures, and it can be active at $10^{\circ} \mathrm{C}$. As the optimal temperature for B. odoriphaga is $15-24{ }^{\circ} \mathrm{C}$ [41], it is important to know whether the selected EPN is still active against the $B$. odoriphaga larvae when the soil temperature decreases. The results showed that $H$. indica LN2 and $H$. indica LN2-imidacloprid combinations were not as effective as treatments containing S. feltiae $\mathrm{SN}$ at 15 and $20^{\circ} \mathrm{C}$, suggesting that $H$. indica LN2 was not as active as S. feltiae SN at 15 and $20^{\circ} \mathrm{C}$. The addition of imidacloprid did not increase the infectivity of $H$. indica LN2 against $B$. odoriphaga at these two temperatures. When temperature increased to $25{ }^{\circ} \mathrm{C}$, the treatments of $H$. indica LN2 and $H$. indica LN2-imidacloprid combination increased the efficacy against $B$. odoriphaga, suggesting that $H$. indica LN2 was more active at a high temperature. Heterorhabditis indica LN2 has also been reported to show poor infectivity against Phyllotreta striolata and Agrotis ipsilon larvae at low temperature [11,42]. Heterorhabditis indica LN2 was first isolated in India, and it has adapted itself to a relatively high temperature where it was recovered [43], which might explain the poor performance of $H$. indica LN2 against pests at low temperatures.

It is the first time to report a year-around occurrence of the B. odoriphaga larvae after treatment with EPN in chive fields. Results showed that treatment of S. feltiae SN-imidacloprid and S. feltiae SN-H. indica LN2-imidacloprid combinations constantly suppress the larval population of $B$. odoriphaga, and this suppression effect could last for almost 11 months in both field experiments. In an experiment conducted in Weifang, treatment of H. indica LN2-imidacloprid combination showed similar suppression effects on the larval population of B. odoriphaga. While in the experiment conducted in Zhangqiu, treatment of H. indica LN2-imidacloprid combination did not show significant suppression effects on the larval population of $B$. odoriphaga when compared with treatments containing S. feltiae SN. Chives were planted under different modes in the two fields. Chives in the field in Weifang were planted under double-sheds. The temperature in the soil was relatively constant and high, so H. indica LN2 could perform well. While in the field in Zhangqiu, the chives were planted under only one layer of protective film. The temperature in this field was not as high as that in Weifang, and the films were removed from February to late October. This might explain why $H$. indica LN2 could not perform as well in the field in Weifang.

Cost and profit are the main factors that farmers or companies concerned about, when EPN are applied. In Zhangqiu, chives harvested from EPN-imidacloprid treatments were sold at a higher price 
than those from chlorbenzuron treatment. Although the cost of the EPN-imidacloprid treatments was 2.0 to 3.6 times higher than that of the chlorbenzuron treatment, and the yield of the chive did not vary much, the profits from the EPN-imidacloprid treatments were 1.7 to 2.4 times as much as those from the chlorbenzuron treatment. The ecological and economic effects were superior in chives produced by EPN-imidacloprid treatments than by chlorbenzuron treatment. In Weifang, where the price of chives was the same in different treatments, the profit was still slightly higher with the EPN-imidacloprid treatments than with the phoxim treatment. The application of EPN-imidacloprid combinations could provide a competitive method for chemical control against $B$. odoriphaga in chive production, regardless of the ecological effects. If chives protected by EPN-imidacloprid treatments could be sold at a higher price than by insecticides, the profit will significantly increase.

\section{Conclusions}

The present study developed a cost-effective management method to control B. odoriphaga in chive production. In chive planting fields furnished with one layer of protective film, two rounds of application of S. feltiae SN-imidacloprid or S. feltiae SN + H. indica LN2 + imidacloprid in one year is recommended for effective $B$. odoriphaga control in the field. In chive planting in a greenhouse furnished with one layer of protective film, two applications of S. feltiae SN or H. indica LN2 with imidacloprid were both recommended for effective $B$. odoriphaga control.

Author Contributions: Conceptualization, R.H.; Funding acquisition, X.Y. and R.H.; Methodology, G.Z.; Writing—original draft, X.Y. and G.Z.; Writing—review \& editing, X.Y. and R.H.

Funding: This research was funded by the National Key Research and Development Program of China, grant number 2017YFD0201200, the Natural Science Foundation of Guangdong Province, China, grant number 2017A030313157 and the GDAS Special Project of Science and Technology Development, grant number 2018GDASCX-0107.

Conflicts of Interest: The authors declare no conflict of interest.

\section{References}

1. Zhang, P.; Liu, F.; Mu, W.; Wang, Q.; Li, H.; Chen, C. Life table study of the effects of sublethal concentrations of thiamethoxam on Bradysia odoriphaga Yang and Zhang. Pestic. Biochem. Phys. 2014, 111, 31-37. [CrossRef] [PubMed]

2. Zhang, P.; Zhao, Y.H.; Wang, Q.H.; Mu, W.; Liu, F. Lethal and sublethal effects of the chitin synthesis inhibitor chlorfluazuron on Bradysia odoriphaga Yang and Zhang (Diptera: Sciaridae). Pestic. Biochem. Phys. 2017, 136, 80-88. [CrossRef] [PubMed]

3. Ma, J.; Chen, S.; Moens, M.; Han, R.; De Clercq, P. Efficacy of entomopathogenic nematodes (Rhabditida: Steinernematidae and Heterorhabditidae) against the chive gnat, Bradysia odoriphaga. J. Pest Sci. 2013, 86, 551-561. [CrossRef]

4. Mei, Z.X.; Wu, Q.J.; Zhang, Y.J.; Hua, L. Life tables of the laboratory population of Bradysia odoriphaga Yang et Zhang (Diptera: Mycetophilidae) at different temperatures. Acta Entomol. Sin. 2004, 47, $219-222$.

5. Zhao, Y.; Wang, Q.; Ding, J.; Wang, Y.; Zhang, Z.; Liu, F.; Mu, W. Sublethal effects of chlorfenapyr on the life table parameters, nutritional physiology and enzymatic properties of Bradysia odoriphaga (Diptera: Sciaridae). Pestic. Biochem. Phys. 2018, 148, 93-102. [CrossRef]

6. Zhao, Y.; Zhang, P.; Zhai, Y.; Chen, C.; Wang, Q.; Han, J.; Liu, F.; Mu, W. Sublethal concentration of benzothiazole adversely affect development, reproduction and longevity of Bradysia odoriphaga (Diptera: Sciaridae). Phytoparasitica 2016, 44, 115-124. [CrossRef]

7. Chen, C.; Shi, X.; Desneux, N.; Han, P.; Gao, X. Detection of insecticide resistance in Bradysia odoriphaga Yang et Zhang (Diptera: Sciaridae) in China. Ecotoxicology 2017, 26, 868-875. [CrossRef]

8. Zhao, Y.; Wang, Q.; Wang, Y.; Zhang, Z.; Wei, Y.; Liu, F. Chlorfenapyr, a potent alternative insecticide of phoxim to control Bradysia odoriphaga (Diptera: Sciaridae). J. Agric. Food Chem. 2017, 65, 5908-5915. [CrossRef] 
9. Yan, X.; Han, R.; Moens, M.; Chen, S.; De Clercq, P. Field evaluation of entomopathogenic nematodes for biological control of striped flea beetle, Phyllotreta striolata (Coleoptera: Chrysomelidae). BioControl 2013, 58, 247-256. [CrossRef]

10. Yan, X.; Guo, W.X.; Zhao, G.Y.; Han, R. Research advances in subterranean pest control by entomopathogenic nematodes. J. Environ. Entomol. 2014, 36, 1018-1024.

11. Yan, X.; Wang, X.; Han, R.; Qiu, X. Utilisation of entomopathogenic nematodes, Heterorhabditis spp. and Steinernema spp., for the control of Agrotis ipsilon (Lepidoptera, Noctuidae) in China. Nematology 2014, 16, 31-40. [CrossRef]

12. Labaude, S.; Griffin, C.T. Transmission success of entomopathogenic nematodes used in pest control. Insects 2018, 9, 72. [CrossRef] [PubMed]

13. Zhao, G. Study on Entomopathogenic Nematodes for the Control of Chive Midge (Diptera: Sciaridae). Master's Thesis, Shandong Agricultural University, Taian, China, 2013.

14. Grewal, P.S.; Wang, X.; Taylor, R.A. Dauer juvenile longevity and stress tolerance in natural populations of entomopathogenic nematodes: Is there a relationship? Int. J. Parasitol. 2002, 32, 717-725. [CrossRef]

15. Guo, W.; Yan, X.; Zhao, G.; Han, R. Increased efficacy of entomopathogenic nematode-insecticide combinations against Holotrichia oblita (Coleoptera: Scarabaeidae). J. Econ. Entomol. 2017, 110, 41-51. [PubMed]

16. Head, J.; Walters, K.F.A.; Langton, S. The compatibility of the entomopathogenic nematode, Steinernema feltiae and chemical insecticides for the control of the South American leafminer Liriomyza huidobrensis. Biocontrol 2000, 45, 345-353. [CrossRef]

17. Cuthbertson, A.; Head, J.; Walters, K.; Murray, A. The integrated use of chemical insecticides and the entomopathogenic nematode, Steinernema feltiae, for the control of sweetpotato whitefly, Bemisia tabaci. Nematology 2003, 5, 713-720. [CrossRef]

18. Koppenhöfer, A.M.; Grewal, P.S. Compatibility and interactions of EPN with other control agents. In Nematodes as Biocontrol Agents; Grewal, P.S., Ehlers, R.U., Shapiro-Ilan, D.I., Eds.; CABI: Wallingford, UK, 2005; pp. 363-381.

19. Cuthbertson, A.G.S.; Mathers, J.J.; Northing, P.; Prickett, A.J.; Walters, K.F.A. The integrated use of chemical insecticides and the entomopathogenic nematode, Steinernema carpocapsae (Nematoda: Steinernematidae), for the control of sweetpotato whitefly, Bemisia tobaci (Hemiptera: Aleyrodidae). Insect Sci. 2008, 15, 447-453. [CrossRef]

20. Rovesti, L.; Deseo, K.V. Compatibility of chemical pesticides with the entomopathogenic nematodes, Steinernema carpocapsae Weiser and S. feltiae Filipjev (Nematoda: Steinernematidae). Nematologica 1990, 36, 237-245. [CrossRef]

21. Koppenhöfer, A.M.; Cowles, R.S.; Cowles, E.A.; Fuzy, E.M.; Baumgartner, L. Comparison of neonicotinoid insecticides as synergists for entomopathogenic nematodes. Biol. Control 2002, 24, 90-97. [CrossRef]

22. Krishnayya, P.V.; Grewal, P.S. Effect of neem and selected fungicides on viability and virulence of the entomopathogenic nematode Steinernema feltiae. Biocontrol Sci. Technol. 2002, 12, 259-266. [CrossRef]

23. Cuthbertson, A.G.S.; Mathers, J.J.; Northing, P.; Luo, W.; Walters, K.F.A. Establishing effect of commonly used insecticides for aphid control on the infectivity of the entomopathogenic nematode Steinernema feltiae using a streamlined screening method. J. Environ. Res. Dev. 2007, 2, 1-5.

24. Koppenhöfer, A.M.; Fuzy, E.M. Effect of the anthranilic diamide insecticide, chlorantraniliprole, on Heterorhabditis bacteriophora (Rhabditida: Heterorhabditidae) efficacy against white grubs (Coleoptera: Scarabaeidae). Biol. Control 2008, 45, 93-102. [CrossRef]

25. Koppenhöfer, A.M.; Fuzy, E.M. Early timing and new combinations to increase the efficacy of neonicotinoid-entomopathogenic nematode (Rhabditida: Heterorhabditidae) combinations against white grubs (Coleoptera: Scarabaeidae). Pest Manag. Sci. 2008, 64, 725-735. [CrossRef] [PubMed]

26. Yan, X.; Moens, M.; Han, R.; Chen, S.; De Clercq, P. Effects of selected insecticides on osmotically treated entomopathogenic nematodes. J. Plant Dis. Prot. 2012, 119, 152-158. [CrossRef]

27. Kamali, S.; Karimi, J.; Koppenhöfer, A.M. New insight into the management of the tomato leaf miner, Tuta absoluta (Lepidoptera: Gelechiidae) with entomopathogenic nematodes. J. Econ. Entomol. 2018, 111, 112-119. [CrossRef]

28. Wu, H.; Gong, Q.; Fan, K.; Sun, R.; Xu, Y.; Zhang, K. Synergistic effect of entomopathogenic nematodes and thiamethoxam in controlling Bradysia odoriphage Yang and Zhang (Diptera: Sciaridae). Biol. Control 2017, 111, 53-60. [CrossRef] 
29. Zhou, X.H.; Zhang, S.C.; Zhuang, Q.Y.; Zhang, A.S.; Li, L.L.; Men, X.Y.; Zhai, Y.F.; Yu, Y. Screening and evaluation of the artificial diets of Bradysia odoriphaga Yang et Zhang (Diptera: Sciaridae). Acta Entomol. Sin. 2015, 58, 1245-1252.

30. Chai, P.C.; Zhang, R.J. Effects of rearing density on growth and development of larvae of Tenebrio molitor. Entomol. Knowl. 2001, 38, 452-455.

31. Liu, S.; Li, K.; Liu, C.; Wang, Q.; Yin, J.; Cao, Y. Identification of a strain of Heterorhabditis (Nematoda: Heterorhabditidae) from Hebei and its virulence to white grubs. Acta Entomol. Sin. 2009, 52, 959-966.

32. Abbott, W.S. A method of computing the effectiveness of an insecticide. J. Am. Mosquito Control 1987, 3, 302. [CrossRef]

33. Koppenhöfer, A.M.; Kaya, H.K. Synergism of imidacloprid and an entomopathogenic nematode: A novel approach to white grub (Coleoptera: Scarabaeidae) control in turfgrass. J. Econ. Entom. 1998, 91, 618-623. [CrossRef]

34. Koppenhöfer, A.M.; Brown, I.M.; Gaugler, R.; Grewal, P.S.; Kaya, H.K.; Klein, M.G. Synergism of entomopathogenic nematodes and imidacloprid against white grubs: Greenhouse and field evaluation. Biol. Control 2000, 19, 245-251. [CrossRef]

35. Koppenhöfer, A.M.; Grewal, P.S.; Kaya, H.K. Synergism of imidacloprid and entomopathogenic nematodes against white grubs: The mechanism. Entomol. Exp. Appl. 2000, 94, 283-293. [CrossRef]

36. Jiao, L. Effects of Temperature on Ecological Features of Bradysia odoriphaga and Biological Activity of Osthol to the Pest. Master's Thesis, Shandong Agricultural University, Taian, China, 2017.

37. Hatab, M.A.A.; Gaugler, R. Lipids of in vivo and in vitro cultured Heterorhabditis bacteriophora. Biol. Control 1999, 15, 113-118. [CrossRef]

38. Caamano, E.X.; Cloyd, R.A.; Solter, L.F.; Fallo, D.J. Quality assessment of two commercially available species of entomopathogenic nematodes: Steinernema feltiae and Heterorhabditis indica. HortTechnology 2008, 18, 84-89. [CrossRef]

39. Hang, T.D.; Choo, H.Y.; Lee, D.W.; Lee, S.M.; Kaya, H.K.; Park, C.G. Temperature effects on Korean entomopathogenic nematodes, Steinernema glaseri and S. longicaudum, and their symbiotic bacteria. J. Microbiol. Biotechnol. 2007, 17, 420-427. [PubMed]

40. Koppenhöfer, A.M.; Ebssa, L.; Fuzy, E.M. Storage temperature and duration affect Steinernema scarabaei dispersal and attraction, virulence, and infectivity to a white grub host. J. Invertebr. Pathol. 2013, 112, 129-137. [CrossRef] [PubMed]

41. Wang, X.; Zhang, B.; Li, Y.; Chen, X.; Wu, J.; Yu, H. Study on occurrence of Bradysia odoriphaga. Tianjin Agric. Sci. Technol. 1995, 133, 12-13.

42. Xu, C.; De Clercq, P.; Moens, M.; Chen, S.; Han, R. Efficacy of entomopathogenic nematodes (Rhabditida: Steinernematidae and Heterorhabditidae) against the striped flea beetle, Phyllotreta striolata. BioControl 2010, 55, 789-797. [CrossRef]

43. Yan, X.; Lin, Y.; Huang, Z.; Han, R. Characterisation of biological and biocontrol traits of entomopathogenic nematodes promising for control of striped flea beetle (Phyllotreta striolata). Nematology 2018, 20, 503-518. [CrossRef]

(C) 2019 by the authors. Licensee MDPI, Basel, Switzerland. This article is an open access article distributed under the terms and conditions of the Creative Commons Attribution (CC BY) license (http://creativecommons.org/licenses/by/4.0/). 